\title{
SOCIAL CAPITAL AND SOCIAL DEVELOPMENT
}

\section{A Nieman \\ INTRODUCTION}

To address the conditions of poverty and underdevelopment in the country, the South African government has accepted the social development approach as policy for delivery of social services. Social welfare organisations and other similar social service providers, such as faith-based organisations (FBOs), have attempted to implement this policy with varying degrees of enthusiasm and success. It has been stated that the transformation of service delivery requires a "...comprehensive reshaping of social work practice" (Green, 1999:29) to bring about the changes that people and communities need to escape the degrading conditions of poverty. In this regard social development encompasses the broad multi-dimensional concepts of planned change towards social and economic well-being, and the improvement of the quality of life for individuals, groups and communities (Billups, 1994; Pandey, 1981; Midgley, 1994).

The idea of social capital as a possible factor that could add value to social development efforts presents a significant challenge to social service practitioners. In this context the networks of social relationships of trust and mutual caring that exist in communities, known as social capital, represent certain strengths that could be utilised and also be cultivated to support social development efforts.

The article thus aims to explore and describe the notion of social capital and its benefits in order to determine its inherent relevance for application in the fields of social work and social welfare. Elements and concepts associated with social development will also be highlighted to determine whether and how social capital can contribute towards the success and sustainability of social development efforts and programmes. Conclusions will be drawn about the potential to build and utilise social capital in order to help communities to change and achieve social development objectives, particularly as this relates to South Africa.

\section{WHAT IS SOCIAL CAPITAL?}

In the absence of a commonly accepted definition (Kliksberg, 2004:32), the idea of what social capital entails will firstly be discussed by identifying forms and characteristics, and highlighting some areas which illustrate the value and benefits that individuals, groups and communities can derive from the networks and relationships that add up to social capital.

Social capital has been described as the "glue" that develops between people in groups and societies by sharing experiences, ideas, ideals, beliefs and practices. According to Coleman (1990:302), social capital is dependent on the social structures that exist between people, which make it possible for those involved to take certain actions and to be able to get things done that they would not have been able to do on their own. Thus, the distinguishing aspect of social capital is that it relies on relationships between people who form the social structures. It is worthwhile noting that the idea of "giving and receiving" is assumed and forms part of such relationships. That implies that social capital is established for a purpose and it will continue for as long as people experience results and benefits from it (Coleman, 2000:16). 


\section{Forms of social capital}

Specific forms of social capital have been identified by Coleman (2000:19-23) to illustrate its difference from physical capital as an economic concept, which is measurable and tangible, and from human capital, which refers to skills and knowledge.

Social capital refers to relationship structures that rely on the obligations, expectations and trustworthiness of those involved. In such structures people would have expectations for reciprocity of benefits or in the sharing of goods, services or other forms of assets or assistance. Trust is an important element in this form of social capital, as the ability of people to work together successfully for common goals depends on the measure of trust that develops between them (Fukuyama, 1995). The close ties that exist in some families, groups or communities serve as an assurance which guarantees the trustworthiness of their activities, whether business or social. A typical example of this form of social capital is found in rotating credit schemes, which requires those taking part to have trust in the other participants that the contributions of their savings will be equally and fairly distributed.

The channels of information that are shared in social relations constitute a meaningful second form of social capital. This implies that information that can be useful for different purposes is easily accessible and can lead to fruitful action. This is particularly valuable for people in poor rural or isolated communities without access to electronic or printed forms of information such as newspapers, other publications or the Internet.

A third form of social capital is the acceptance of norms that support and reward positive behaviour, while penalising negative behaviour. Norms therefore become meaningful instruments to actually encourage and facilitate certain behaviour and actions, and discourage others. This implies that the social capital of residents can inhibit negative behaviour and encourage positive conduct in a community. It would mean that, for example, the social relations between residents who disapprove of crime, along with their accepted norms which encourage certain patterns of behaviour, can assist in combating criminal activities and help to ensure safe environments.

\section{Benefits of social capital}

The advantages offered by social capital to individuals, families and communities have been well documented. Some areas where the availability and contribution of social capital are found to be of particular value and meaning for South African conditions are the following:

- The concepts of sharing and group cohesiveness found in the spirit of ubuntu, the South African term referring to "brotherly love and group care" illustrate the value of a combination of the forms of social capital. The key values of ubuntu, namely "group solidarity, conformity, compassion, respect, human dignity and collective unity" (Mbigi \& Maree, 1995:2) serve an important function to build the networks and norms through trust and cooperation, considered as the "main elements" of social capital by Putnam (in Gittel \& Vidal, 1998:15).

- Some of the negative effects of poverty are the break-up of family life, which often leads to poor performance or children dropping out of school. This means children also miss out on the inherent resources in families and community life that exist in the norms and trusting relationships that contribute to their development (Loury in Coleman, 1990:300). Stable, healthy family relations are an important form of social capital for young people and a strong 
parental presence is a significant asset for shaping behaviour patterns and for performance at school. Thus social capital in the family can be seen as a significant resource for education, as was found in a study by Israel and Beaulieu (2004) to measure how social capital available in family, school and community can help children stay in school. It was found that children who are part of caring, stable family environments and who also take part in religious community group activities perform well and stay in school longer, even in low-income communities. These "striking benefits" of social capital (Israel \& Beaulieu, 2004:36-49) become especially significant when parents take an interest in the child's performance and future expectations, and also become involved in school activities.

- The fact that social capital relies on social relations formed for a purpose implies that the benefits of social capital can be purposely created. Such relations and networks have the potential to be "dynamic bundles of assets" (Murphy \& Cunningham, 2003:204) for social service providers when dealing with poor communities. A study by Donaldson (in Mikell, 1997) describes the supporting and sustaining networks found amongst women in Tsunyane, a remote, poor rural town in South Africa, to prove the advantages they derived from social capital. These female networks provided mutual assistance during illnesses in the absence of proper health care facilities, as well as emotional and practical support. Based on the strong bonds of sisterhood that prevailed, they were able to survive severe hardships by relying on networks of unrelated female neighbours and friends.

\section{Levels of social capital}

Levitte (2004) and Saegert, Thompson and Warren (2001) provide useful insights for application in work with poor communities with few resources by describing different levels of social capital and by indicating that communities, like individuals, benefit when they pool their resources. The levels or types of social capital formed for different purposes and the potential benefits that flow from these are bonding, bridging and linking capital.

- Bonding social capital is formed by the close relationships between people such as family members, neighbours and intimate friends (Gittel \& Vidal, 1998; Woolcock, 2000; Narayan in Levitte, 2004). Churches are described as the best-known and most common type of institutions that serve as sources of bonding social capital, particularly in low-income communities. Not only do they provide spiritual leadership to their members, but they also often serve as sources for support and caring for the broader needs of their members, which often include material needs (Saegert et al., 2001:10).

- Bridging social capital is formed between people who are not well known to one another, such as people working together or living in the same neighbourhood or town. Several types of bridging capital are identified by Saegert et al. (2001) to show that, by building relationships between different groups and communities, trust and cooperation can develop. The authors are of the opinion that churches can play an important role in "bridge-building" programmes by facilitating interchange between affluent and poor communities. This will help to improve understanding between different levels of society as well as provide networks to external resources. Similarly, schools can create bridging social capital, if they create opportunities for children and parents from different backgrounds and income groups to interact jointly in school projects (Saegert et al., 2001:12-13). Through such interactions new ideas and resources can be passed on and can even create possible additional funding opportunities for school projects and bursaries. 
- Linking social capital refers to relationships that are created beyond the community borders by reaching out to institutions and facilities outside the immediate environment. Such outreach efforts are necessary when additional sources need to be approached for resources such as information, new ideas and access to training (Woolcock in Levitt, 2004:46). Deliberate efforts to build this type of social capital require public institutions to work together and form relationships with local role players in an attempt to address problems of underdevelopment and inadequate resources.

The concept of social capital has been shown to hold benefits for families, groups and communities and, when acknowledged, the relationships of trust and cooperation can be leveraged for social development initiatives. The manner in which social capital can be harnessed and utilised when social development initiatives and programmes are planned and initiated will be highlighted in the context of what would constitute success for social development programmes.

\section{LINKING SOCIAL CAPITAL AND SOCIAL DEVELOPMENT}

In this section an attempt will be made to explore the relationship and links between social capital and social development. In view of the benefits and qualities found in the "glue" of social capital, as described above, it would be advantageous for welfare organisations and social workers to identify and utilise existing social capital when they are planning social development programmes.

A Country Report on South Africa by the World Bank claims that the disparities existing in this country are among "the most extreme in the world" (The World Bank Group, 2000:1). To deal with the problems that result from the large proportion of poor and unemployed people in the country, the South African government has accepted transformation as a priority responsibility for its policies and programmes by publishing The White Paper for Social Welfare (Department of Welfare, 1997). Emphasising the social development perspective, the White Paper provides the policy framework for developmental welfare services. Thus, social service providers, who have to implement the developmental approach in interventions when dealing with poverty and the problems related to it, face different choices for such interventions. Social capital has been shown to represent meaningful community resources, so community development and community work would seem realistic options for practitioners to implement social development programmes.

Against this background the following elements or themes present in successful social development programmes, which can be considered as good-practice criteria, have been identified on the grounds of their relevance to social capital:

- Participation in planning, decision making and implementation;

- Groups, groupings and networks;

- $\quad$ Learning, training and the acquiring of knowledge.

\section{Participation}

Participation can be seen as the backbone of social development. It promotes inclusiveness, empowerment and decisions of consequence. It has been referred to both as a process and a product (Murphy \& Cunningham, 2003:111) as it demands continuous effort, but also produces outcomes, achievements and growth. Organisations with broad representation, whose members 
decide on the agenda and programmes, are likely to have more support and credibility within the community, with the authorities and with funding bodies (Gittel \& Vidal, 1998:175).

The following significant advantages of grassroots participation offered by Abatena (1997) provide useful guidelines for social service providers when they consider interventions aimed at social development.

Firstly such participation ensures "appropriate problem diagnosis and clear definition of the problem", which will in turn help to decide on "appropriate and feasible solutions" (Abatena, 1997:17).

Secondly, being involved in and actively participating when deciding on solutions allows for a wider range of possible solutions, also for consideration of the practical aspects of implementing them as well as what the benefits are that they want and, importantly, who the main beneficiaries are going to be, thereby cutting out the bad practices of growing bureaucracies and a few benefiting at the cost of the rest.

Thirdly, participating in decision making about solutions helps to ensure successful implementation, because people are more agreeable about doing the things they themselves have decided on or helped others decide on. Programmes also stand a better change of being sustained because of the community's self-interest in them, their sense of pride and the personal learning benefits they experience. Successful implementation of initial programmes also often leads to their being expanded into other initiatives and projects.

To avoid the trap of glib, artificial participatory methods and to demonstrate the complexity and difficulty of building solid participation, Arnstein's Ladder (Murphy \& Cunningham, 2003:112) is seen as a useful model to measure client involvement in community development programmes. Table 1 represents the adapted model for such measurement.

TABLE 1

ARNSTEIN'S LADDER OF CITIZEN PARTICIPATION

\begin{tabular}{|l|}
\hline Partnership \\
\hline Placation \\
\hline Consultation \\
\hline Informing \\
\hline Therapy \\
\hline Manipulation \\
\hline
\end{tabular}

Source: Adapted from Arnstein 1969 (in Murphy \& Cunningham, 2003:112)

In the model the bottom rungs labelled manipulation and therapy illustrate non-participation. Manipulation refers to "rubber-stamp" decisions taken without any consultation, while therapy indicates social services where participation has no role. The following three rungs of the ladder, namely informing, consultation and placation, are all viewed as stages of tokenism, with consultation usually referring to opinion surveys. Placation relates to token membership in committees and on boards or allocating functions to people without providing supporting resources such as technical help and finance. The next rung, partnership, implies negotiated decision-making following on adequate provision of assistance such as legal, financian and technical expertise in order for participants to be able to make informed decisions. 
Although this model may appear somewhat over-simplified, it is nevertheless helpful to illustrate the barriers and complications that need to be considered when striving for true participation in community and social development work. One such barriers may be a lack of resources, which is often a problem for service providers. Consequently, social welfare organisations wanting to build partnerships in a community have to realise the need to provide or facilitate sufficient access to technical and administrative assistance as well as funding sources. Such endeavours would have the further benefits of helping to build bridging as well as linking capital in a community.

Resources represent power and parity to form partnerships with institutions or other projects which is often required to extend or improve the programme. By empowering community members with knowledge, skills, access to information and other relevant learning opportunities, they become able to move up the "ladder of citizen participation".

Murphy and Cunningham (2003:117) describe the following practical ways for social service practitioners to encourage participation in community development programmes:

- Give recognition to volunteers;

- Build pride by educating people, for example, on how to, and who to, approach about community issues;

- Have regular meetings as learning opportunities where “...they should come out excited, feeling they can control their own lives";

- Have regular neighbourhood celebratory events with music, dance and poetry.

Efforts at ensuring full and meaningful participation when starting and running social development projects will have the further benefits of encouraging the flow of information and building trust and bonds between community members, thus strengthening the social capital in the community.

\section{Groups and organisations}

Membership of groups and organisations as a staple of social capital as well as social development projects is well documented. Putnam (1993) views the benefits of formal and informal, social and cultural groups as worthwhile networks, which can ultimately lead to economic prosperity for their members. Groups also represent the "bonding capital" which exists between people who know and trust one another (Putnam in Gittel \& Vidal, 1998:15) and which serves as a cohesive advantage for their members.

The continued value and popularity of groups in Southern Africa is shown in a study by Haddad and Maluccio (2003), who found that group membership increased by 65\% during the period 1993 to 1998 . The average group membership of $0,8 \%$ of the population in 1993 increased to $1,35 \%$ in 1998. Amongst the groups showing the biggest increases were financial groups, including stokvels and burial societies as well as religious organisations, which scored the highest membership (Haddad \& Maluccio, 2003:573). A large section of the religious affiliations refer to the African Independent Churches, which are often also associated with financial support schemes, similarly to many women's support groups.

\section{Types of groups}

Church groups and religious movements have traditionally formed valuable resources for support and strength in community and social development work. In the last census $84 \%$ of the South African population indicated membership of a church (Statistics South Africa, 2004). This proves the potentially strong voice and power represented by churches, which could be harnessed as an ally in projects to deal with poverty. Schorr (in Murphy \& Cunningham, 2003) places great value 
on the benefits that religious organisations can bring to development programmes as movements representing core values. The value of incorporating spiritual and faith-based organisations into social change programmes has been widely hailed as "providing the extra element that makes it possible to persevere", as being a foundation "that allows for trust as its starting point" and for combining "religion and opportunism" (Schorr in Murphy \& Cunningham, 2003: 212-213). There seems to be general consensus that church-based organisations should be an important and necessary component in all community and social development efforts.

Informal rotating-credit groups were found in a World Bank study to be particularly popular and were ranked by some participants as the most important local institution (Narayan, Chambers, Shah \& Petesch, 2000:57). As informal social institutions, credit savings schemes, also called stokvels in South Africa, were found to be the most common groups for decades (Moser, 1999:vi).

Moser (1999) describes the significant roles played by organisations such as the union movement, the civics movement, the Black Consciousness Movement and the Mass Democratic Movement in bringing about political change in South Africa as examples of the strengths for change that social capital represents.

Farmer representative bodies, as an important form of social capital in development projects, could be another noteworthy example of drawing on the "collective consciousness" (Uphoff, 2000:234) of its members. The author describes how a farming area in Sri Lanka, which was considered as the "most deteriorated, disorganised ... and most conflicted" (Uphoff, 2000:233-239), was turned around by the formation of farmer representative bodies, which mobilised to co-operate, thus resulting in improved water conservation, better crops and improved living conditions. The farmers attributed their successful turnaround to the structure of their organisation and to the interaction and sharing that led them to develop pride in their work. The social capital that was created through their cooperative efforts sustained the group when they later also experienced harsher circumstances, like a severe drought.

\section{Training}

The processes of learning and acquiring knowledge and skills form part of all social development programmes and projects. In South Africa, “...because of the legacy of the past, there is an exceptionally large need... [to] eliminate the disempowerment of ignorance by improving the literacy and skills levels of communities" (Weyers, 2001:162-163). Training and education thus form a particularly significant part of community work. A variety of techniques to implement learning opportunities include formal training, educational group work, workshops, drama and theatre as well as the use of visual material, special events and programmes (Weyers, 2001:167187).

Welfare organisations and other social service providers that initiate "community economic development programmes" (Lombard, 2003:224-237) have an important role as facilitators for skills and capacity development. To identify training needs, and to find and negotiate facilities and opportunities for community members to develop knowledge and skills, are basic requirements to fulfil. Skills training should include inter alia learning to write business plans or funding proposals, bookkeeping knowledge, marketing as well as the technical skills required for a specific project. In many cases adult education opportunities should form part of new programmes. Such training and networking activities form important building blocks for the development of social capital in a community, considered as of "crucial importance" for the success of such projects (Carton et al. in Lombard, 2003:234). Individuals and communities thus become empowered to take collective responsibility for their endeavours and projects. 
People who train and work together towards the success of social development programmes build social capital through trust and sharing in the obligations and expectations of "their" projects. By developing standards of quality and norms of behaviour, important forms of social capital are cultivated.

\section{CONCLUSIONS}

The different forms of social capital and its benefits as they relate to social services have been identified.

Sources of social capital have been shown to exist in different South African community networks and associations. Such sources are church memberships, women's groups, political party memberships and members of rotating savings schemes (stokvels). It appears that social service providers could utilise these and other similar groups in community development efforts by harnessing the relationships of trust, mutual caring and support that exist for the sake of social and economic change for social development purposes.

Social capital can further be cultivated if special attention is given to good practice guidelines when programmes aimed at social development are planned and implemented. Thus social welfare organisations and FBOs can assist and empower communities suffering from the effects of poverty, when they identify and acknowledge existing strengths in families and community groups and initiate efforts to build and strengthen such sources of social capital through social development programmes. These programmes will stand a good chance of being sustainable, if the benefits of social capital are acknowledged and put to use.

\section{REFERENCES}

ABATENA, H. 1997. The significance of planned community participation in problem solving and developing a viable community capability. Journal of Community Practice, 4(2):13-34.

BILLUPS, J. 1994. The social development model as an organizing framework for social work practice. Encyclopedia of Social Work, 19(3):2169-2172.

COLEMAN, J. 1990. Foundations of social theory. Cambridge. The Belknap Press of Harvard University Press

COLEMAN, J.S. 2000. Social capital in the creation of human capital. In: DASGUPTA, P. \& SERAGELDIN, I. Social Capital. A multifaceted perspective. Washington. The World Bank.

DEPARTMENT OF WELFARE 1997. White paper on social welfare. Government Gazette, Notice 57 of 1996. Pretoria. Government Printer.

DONALDSON, S.R. 1997. “Our women keep our skies from falling”: Women's networks and survival imperative in Tshunyane, South Africa. In: MIKELL, G. (ed) African feminism. The politics of survival in Sub-Saharan Africa. Philadelphia. University of Pennsylvania Press: 257274.

FUKUYAMA, F.K. 1995. Trust. The social virtues and creation of prosperity. London: Hamish Hamilton.

GITTEL, R. \& VIDAL, A. 1998. Community organizing. Building social capital as a development strategy. Thousand Oaks: Sage Publications. 
GREEN, S. 1999. The matrix of social work practice: Implications for the transformation of social work education. Social Work/Maatskaplike Werk, 35(1):29-37.

HADDAD, L. \& MALUCCIO, J.A. 2003. Trust, membership in groups and household welfare: Evidence from KwaZulu-Natal, South Africa. Economic Development and Cultural Change, 51(3):572-573.

ISRAEL, G.D. \& BEAULIEU, L.J. 2004. Investing in communities: Social capital's role in keeping youth in school. Journal of the Community Development Society, 34(2):35-57.

KLIKSBERG, B. 2004. The role of social and cultural capital in the development process. Transnational Associations, Jan./March 2004:32-57.

LEVITTE, Y. 2004. Bonding social capital in entrepreneurial developing communities - survival networks or barriers? Journal of the Community Development Society, 35(2):44-64.

LOMBARD, A. 2003. Entrepreneurship in Africa: Social work challenges for human, social and economic development. Social Work/Maatskaplike Werk, 39(3):224-239.

MBIGI, L. \& MAREE, J. 1995. Ubuntu: The spirit of African transformation management. Randburg. Knowledge Resources.

MIDGLEY, J. 1994. Defining social development: Historical trends and conceptual formulations. Encyclopedia of Social Work, 19(3):2169-2172.

MIDGLEY, J.M. 1995. Social development. A developmental perspective in social work. London: Sage.

MOSER, C. M. 1999. Violence and poverty in South Africa: Their impact on household relations and social capital. South Africa: Poverty and inequality. Informal discussion paper. Washington. The World Bank.

MURPHY, P. \& CUNNINGHAM, J.V. 2003. Organising for community controlled development. Renewing civil society. Thousand Oaks: Sage Publications.

NARAYAN, D., CHAMBERS, R., SHAH, M. \& PETESCH, P. 2000. Voices of the poor crying out for change. Washington: Oxford University Press.

PANDEY, R. 1981. Strategies for social development. Encyclopedia of Social Work, 19(3):2169-2172.

PUTNAM, R.D. 1993. Making democracy work. Civic traditions in modern Italy. Princeton: Princeton University Press.

SAEGERT, S., THOMPSON, J.P. \& WARREN, M.R. 2001. Social capital and poor communities. New York: Russell Sage Foundation.

STATISTICS SOUTH AFRICA, 2004. Census 2001. Pretoria: Government Printer.

THE WORLD BANK GROUP 2000. Countries: South Africa. Washington.

UPHOFF, N. 2000. Understanding social capital: Learning from the analysis and experience of participation. In: DASGUPTA, P. \& SERAGELDIN, I. (eds) Social capital. A multifaceted perspective. Washington: The World Bank. 
WEYERS, M.L. 2001. The theory and practice of community work. A South African Perspective. Potchefstroom: Keurkopie.

WOOLCOCK, M. 2000. Social capital in theory and practice: Where do we stand? Paper presented at the $21^{\text {st }}$ Annual Conference on Economic Issues: The Role of Social Capital in Determining Well-Being: Implications for the Teaching and Practice of Development and Environmental Economics. Dept. of Economics, Middlebury College, Middlebury. In: LEVITTE, Y. 2004. Bonding social capital in entrepreneurial developing communities - survival networks or barriers? Journal of the Community Development Society, 35(2):44-64.

Ms Anna Nieman, Department of Social Work, Stellenbosch University, Stellenbosch, South Africa. 